\author{
Marquette University \\ e-Publications@Marquette
}

\title{
Resonance Raman Detection of the Hydroperoxo Intermediate in the Cytochrome P450 Enzymatic Cycle
}

Piotr J. Mak

Marquette University, piotr.mak@marquette.edu

Ilia G. Denisov

University of Illinois at Urbana-Champaign

Doreen Victoria

University of Illinois at Urbana-Champaign

Thomas M. Makris

University of Illinois at Urbana-Champaign

Tianjing Deng

Marquette University

See next page for additional authors

Follow this and additional works at: https://epublications.marquette.edu/chem_fac

Part of the Chemistry Commons

\section{Recommended Citation}

Mak, Piotr J.; Denisov, Ilia G.; Victoria, Doreen; Makris, Thomas M.; Deng, Tianjing; Sligar, Stephen G.; and Kincaid, James R., "Resonance Raman Detection of the Hydroperoxo Intermediate in the Cytochrome P450 Enzymatic Cycle" (2007). Chemistry Faculty Research and Publications. 405.

https://epublications.marquette.edu/chem_fac/405 


\section{Authors}

Piotr J. Mak, llia G. Denisov, Doreen Victoria, Thomas M. Makris, Tianjing Deng, Stephen G. Sligar, and James R. Kincaid

This article is available at e-Publications@Marquette: https://epublications.marquette.edu/chem_fac/405 


\title{
Resonance Raman Detection of the Hydroperoxo Intermediate in the Cytochrome P450 Enzymatic Cycle
}

\author{
Piotr J. Mak \\ Department of Chemistry, Marquette University, \\ Milwaukee, WI \\ Ilia G. Denisov \\ Department of Biochemistry, Center for Biophysics and \\ Computational Biology, and the Beckman Institute, \\ University of Illinois, \\ Urbana-Champaign, IL \\ Doreen Victoria \\ Department of Biochemistry, Center for Biophysics and \\ Computational Biology, and the Beckman Institute, \\ University of Illinois, \\ Urbana-Champaign, IL \\ Thomas M. Makris \\ Department of Biochemistry, Center for Biophysics and \\ Computational Biology, and the Beckman Institute, \\ University of Illinois, \\ Urbana-Champaign, IL
}


NOT THE PUBLISHED VERSION; this is the author's final, peer-reviewed manuscript. The published version may be accessed by following the link in the citation at the bottom of the page.

\author{
Tianjing Deng \\ Department of Chemistry, Marquette University, \\ Milwaukee, WI \\ Stephen G. Sligar \\ Department of Biochemistry, Center for Biophysics and \\ Computational Biology, and the Beckman Institute, \\ University of Illinois, \\ Urbana-Champaign, IL \\ James R. Kincaid \\ Department of Chemistry, Marquette University, \\ Milwaukee, WI
}

\title{
Abstract
}
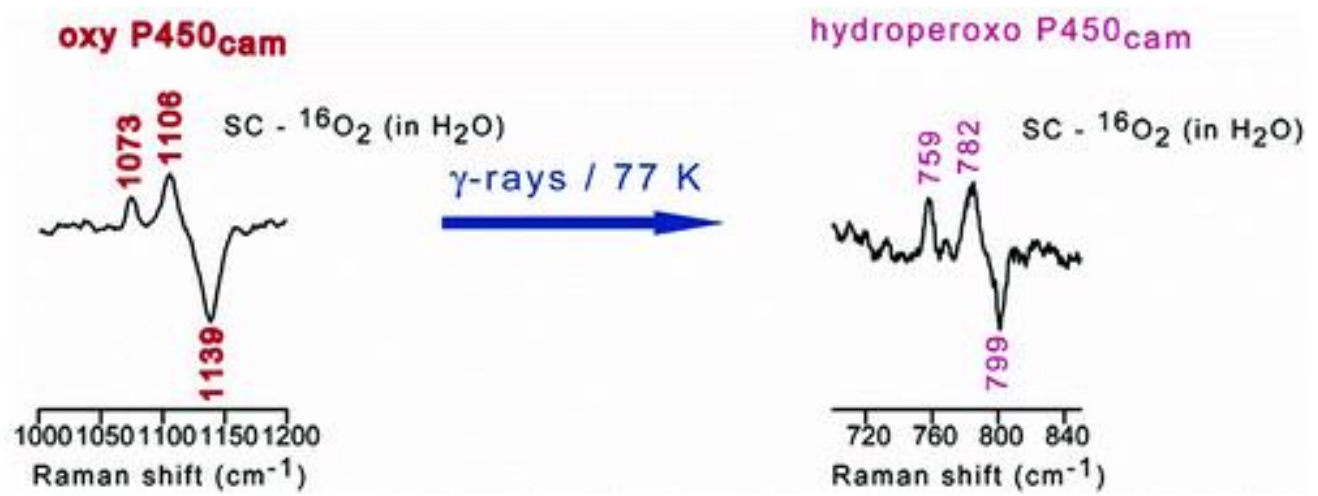

The resonance Raman spectra of the hydroperoxo complex of camphor-bound CYP101 have been obtained by cryoradiolytic reduction of the oxygenated ferrous form that had been rapidly frozen in water/glycerol frozen solution; EPR spectroscopy was employed to confirm the identity of the trapped intermediate. The $\mathrm{v}(\mathrm{O}-\mathrm{O})$ mode, appearing at $799 \mathrm{~cm}^{-1}$, is observed for the first time in a peroxo-heme adduct. It is assigned unambiguously by employing isotopomeric mixtures of oxygen gas containing $50 \%{ }^{16} \mathrm{O}^{18} \mathrm{O}$, confirming the presence of an intact $\mathrm{O}-\mathrm{O}$ fragment. The $\mathrm{v}(\mathrm{Fe}-\mathrm{O})$ mode is observed at $559 \mathrm{~cm}^{-1}\left(\mathrm{H}_{2} \mathrm{O}\right)$. Furthermore, both modes shift down by $3 \mathrm{~cm}^{-1}$, documenting the formulation as a hydroperoxo complex, in agreement with EPR data. 
The cytochromes P450 heme-thiolate enzymes facilitate quite difficult chemical transformations through a multistep reaction cycle that culminates in the generation of a remarkably potent oxidizing species capable of hydroxylating even inert substrates. ${ }^{1-3}$ Following substrate binding to the resting state ferric enzyme, two sequential one-electron reductions bracketing the binding of molecular oxygen and a subsequent proton delivery step lead to heterolytic $\mathrm{O}-\mathrm{O}$ bond cleavage and formation of a highly reactive ferryl heme species comparable to the so-called Compound I intermediate of peroxidases. ${ }^{4-}$ ${ }^{6}$ Thus, key precursors to this critical cleavage reaction are activated heme-bound peroxo and hydroperoxo fragments; that is, (protoporphyrin) $\mathrm{Fe}(\mathrm{III})\left(\mathrm{O}_{2}{ }^{2-}\right)$ or $\mathrm{Fe}(\mathrm{III})\left(\mathrm{O}-\mathrm{OH}^{-}\right)$. A useful approach to access and study these species is to generate and trap the relatively stable oxy-ferrous P450 complex and then to subject the cryotrapped (77 K) sample to radiolytic reduction using radiation from synchrotron, ${ }^{60} \mathrm{Co}$ Y-ray, or ${ }^{32} \mathrm{P}$ sources. ${ }^{7,8}$ Enzymatic intermediates produced by cryoradiolytic reduction of the oxygenated complex of cytochrome P450 cam (CYP101) have been detected by both electronic absorption and EPR spectroscopic methods. $7,9,10$ However, critical mechanistic information has been missing, and it is now important to attempt to provide more detailed structural characterization of the active sites of these species.

Resonance Raman (RR) spectroscopy is an especially attractive probe of such species, effectively interrogating both the heme macrocycle structure and various iron-ligand fragments. ${ }^{11-15}$ In fact, the feasibility of coupling this powerful spectroscopic probe with cryogenic radiolysis of heme protein samples was recently demonstrated and suggested to be a promising new approach to structurally characterize these important intermediates. ${ }^{3,14,15}$ The present work uses RR to provide the first direct observation of the structure-sensitive internal vibrational modes of the $(\mathrm{Fe}-\mathrm{OOH})$ fragment of the hydroperoxo-ferric intermediate of the CYP101 enzyme.

Samples of the oxygenated form of CYP101 were prepared by bubbling dioxygen gas through $30 \%$ glycerol/buffer solutions of the (ferrous) enzyme contained in $5 \mathrm{~mm}$ NMR tubes. The tube was shaken for several seconds to ensure efficient mixing and quickly frozen in 
liquid nitrogen. The RR spectra of these trapped $\mathrm{O}_{2}$ adducts are entirely consistent with those published previously, ${ }^{16-18}$ with some slight shifts to higher frequency being due to low-temperature effects. The spectrum of the ${ }^{16} \mathrm{O}_{2}$-ligated form, shown in trace A of Figure 1 , exhibits the strong $v\left({ }^{16} \mathrm{O}-{ }^{16} \mathrm{O}\right)$ band at $1139 \mathrm{~cm}^{-1}$, as expected. ${ }^{16-18}$ Trace $B$ shows the difference spectrum obtained by subtraction of the spectra of the ${ }^{18} \mathrm{O}_{2}$ and ${ }^{16} \mathrm{O}_{2}$ samples, while trace $\mathrm{C}$ shows the difference spectrum observed for the ${ }^{16} \mathrm{O}_{2} / \mathrm{H}_{2} \mathrm{O}$ and ${ }^{16} \mathrm{O}_{2} / \mathrm{D}_{2} \mathrm{O}$ samples, the latter confirming the lack of a shift for these dioxygen-ligated forms in $\mathrm{D}_{2} \mathrm{O}$ buffers, also as expected. ${ }^{16-18}$ The above RR spectral data confirm the integrity of the samples of $\mathrm{O}_{2}$ adducts. For reasons described below, it was decided to include samples prepared from socalled "scrambled" mixtures of $\mathrm{O}_{2}$ isotopomers, such as [1:2:1] mixtures of $\left[{ }^{16} \mathrm{O}_{2}:{ }^{16} \mathrm{O}^{18} \mathrm{O}:{ }^{18} \mathrm{O}_{2}\right]$. These mixtures were prepared as described elsewhere. ${ }^{19}$ Thus, trace $D$ exhibits a spectral pattern expected for that of the ${ }^{16} \mathrm{O}_{2}$-ligated species subtracted from that of the adduct formed from the scrambled isotopic mixture, the negative peak in the region of the $\left.v^{16} \mathrm{O}-{ }^{16} \mathrm{O}\right)$ resulting from combination of positive and negative $v\left({ }^{16} \mathrm{O}-{ }^{16} \mathrm{O}\right)$ features in a $1: 4$ ratio; that is, the scrambled mixture contains only $25 \%{ }^{16} \mathrm{O}_{2}$. Similarly, trace $\mathrm{E}$ exhibits the expected pattern for the difference spectrum indicated.

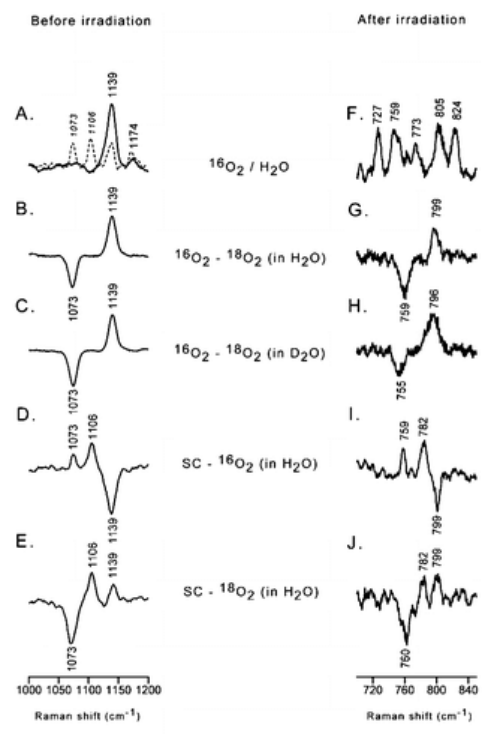

Figure 1 Left panel: RR spectrum of ${ }^{16} \mathrm{O}_{2}$ CYP101 in 30\% glycerol/buffer before irradiation $(A) ;{ }^{16} \mathrm{O}_{2}-{ }^{18} \mathrm{O}_{2}$ in glycerol/buffer $(\mathrm{B}) ;{ }^{16} \mathrm{O}_{2}-{ }^{18} \mathrm{O}_{2}$ in deuterated glycerol/buffer (C); scrambled ${ }^{16} \mathrm{O}_{2}$ in glycerol/buffer (D); scrambled ${ }^{18} \mathrm{O}_{2}$ in deuterated glycerol/buffer (E). Right panel: RR spectrum of 
NOT THE PUBLISHED VERSION; this is the author's final, peer-reviewed manuscript. The published version may be accessed by following the link in the citation at the bottom of the page.

${ }^{16} \mathrm{O}_{2}$ CYP101 in 30\% glycerol/buffer after irradiation $(\mathrm{F}) ;{ }^{16} \mathrm{O}_{2}-{ }^{18} \mathrm{O}_{2}$ in glycerol/buffer $(\mathrm{G}) ;{ }^{16} \mathrm{O}_{2}-{ }^{18} \mathrm{O}_{2}$ in deuterated glycerol/buffer $(\mathrm{H}) ;$ scrambled ${ }^{16} \mathrm{O}_{2}$ in glycerol/buffer (I); scrambled ${ }^{18} \mathrm{O}_{2}$ in deuterated glycerol/buffer (J). Dashed line in trace $A$ is for the sample with scrambled oxygen.

These samples also exhibit the features expected for the $\mathrm{v}\left(\mathrm{Fe}-{ }^{16} \mathrm{O}\right)$ and $\mathrm{v}\left(\mathrm{Fe}-{ }^{18} \mathrm{O}\right)$ modes of the $\mathrm{Fe}-\mathrm{O}_{2}$ fragments (Supporting Information, Figure S1), showing a positive feature at $546 \mathrm{~cm}^{-1}$ for the former and at $515 \mathrm{~cm}^{-1}$ for the latter, frequencies near those previously observed for these adducts in solution at $4{ }^{\circ} \mathrm{C} .17,18$ It is also noted that these lowered frequencies, relative to corresponding values observed near $570 \mathrm{~cm}^{-1}$ for hemoglobin and myoglobin, are also consistent with expectations based on consideration of the trans-axial ligand effects, as has been carefully considered by Babcock and coworkers. ${ }^{20}$

These frozen oxygenated samples were then irradiated with a ${ }^{60} \mathrm{Co} \mathrm{y}$-source to produce the reduced hydroperoxo forms; the EPR spectra confirmed the conversion with approximately $60 \%$ yield (Figure S2). The RR spectra were acquired using the $442 \mathrm{~nm}$ excitation line, a wavelength in closer resonance with the Soret band of the hydroperoxo form. ${ }^{9}$ We note that attempts to acquire the RR spectra of the reduced (i.e., hydroperoxo) form with the $413 \mathrm{~nm}$ excitation yielded only the spectral lines of residual $\mathrm{O}_{2}$ adducts.

The RR spectra acquired for the $\mathrm{y}$-irradiated samples are shown in traces $\mathrm{F}-\mathrm{J}$. In trace $\mathrm{F}$, it is seen that there are multiple resonanceenhanced heme modes in this region; in fact, casual inspection of the absolute spectra in this spectral region provides no clear indication of modes associated with the $\mathrm{Fe}-\mathrm{O}-\mathrm{O}$ fragment of a peroxo formulation. However, as can be seen in traces $G_{-}$J, upon subtraction of the overlapping heme macrocycle modes, the ${ }^{16} \mathrm{O} /{ }^{18} \mathrm{O}$ difference features attributable to such a fragment are clearly evident; that is, the $40 \mathrm{~cm}^{-1}$ shift indicated by the positive and negative components shown in trace $\mathrm{G}$ is entirely consistent with that expected for the $\mathrm{v}(\mathrm{O}-\mathrm{O})$ mode of an Fe-O-O fragment of a peroxo/hydroperoxo formulation. ${ }^{21-24}$ However, bands observed near this frequency region, which also exhibit comparable ${ }^{16} \mathrm{O} /{ }^{18} \mathrm{O}$ shifts, have also been observed for $\mathrm{Fe}(\mathrm{IV})=\mathrm{O}$ fragments in Compound I and Compound II derivatives of various heme proteins, and without additional experimental data, there might 
be lingering ambiguity regarding the nature of the species observed in the present experiments. ${ }^{11-13}$

A conclusive set of experiments is realized, however, by employing the scrambled isotopomeric mixture mentioned earlier; that is, the $1: 2: 1$ mixture of $\left({ }^{16} \mathrm{O}_{2}:{ }^{16} \mathrm{O}^{18} \mathrm{O}:{ }^{18} \mathrm{O}_{2}\right)$. Thus, the revealing patterns observed in traces $\mathrm{I}$ and $\mathrm{J}$ for the scrambled ${ }^{16} \mathrm{O}_{2}$ and scrambled ${ }^{18} \mathrm{O}_{2}$ difference traces, respectively, confirm the fact that the oxygen isotope-sensitive modes represent species with intact $\mathrm{O}-\mathrm{O}$ fragments; these difference traces are consistent only with an $\mathrm{Fe}-\mathrm{O}-\mathrm{O}^{-}$fragment and not an $\mathrm{Fe}=\mathrm{O}$ fragment, for which only a twoband difference pattern would be observed. Furthermore, comparison of difference traces $\mathrm{G}$ and $\mathrm{H}$ shows that both the $\mathrm{v}\left({ }^{16} \mathrm{O}-{ }^{16} \mathrm{O}\right)$ and the $\mathrm{v}\left({ }^{18} \mathrm{O}-{ }^{18} \mathrm{O}\right)$ modes, observed at 799 and $759 \mathrm{~cm}^{-1}$ in $\mathrm{H}_{2} \mathrm{O}$ solutions, shift down to 796 and $755 \mathrm{~cm}^{-1}$, respectively, in deuterated glycerol buffers. These shifts are quite comparable to those observed for other $\mathrm{M}-\mathrm{OOH}(\mathrm{D})$ fragments, supporting the formulation of this intermediate as a hydroperoxo species. ${ }^{21-24}$

As is shown in Supporting Information (Figure S3), the lowfrequency spectra also exhibit new ${ }^{16} \mathrm{O} /{ }^{18} \mathrm{O}$ isotopic-sensitive bands at $559 / 532 \mathrm{~cm}^{-1}$ that are most reasonably assigned to the $\mathrm{v}(\mathrm{Fe}-\mathrm{O})$ modes of an $\mathrm{Fe}-\mathrm{OOH}(\mathrm{D})$ fragment, based on a $3 \mathrm{~cm}^{-1}$ shift in $\mathrm{D}_{2} \mathrm{O}$ and comparisons with other such species. ${ }^{14,15}$ Thus, the present results indicate that the $\mathrm{v}(\mathrm{Fe}-\mathrm{O})$ bond is stronger for the hydroperoxo species relative to the nonreduced oxy complex, based on a shift of $13 \mathrm{~cm}^{-1}$ to higher frequency. This shift is somewhat smaller, however, than the $\sim 45 \mathrm{~cm}^{-1}$ shift observed for hydroperoxo myoglobin, relative to oxy myoglobin. ${ }^{14}$

This observation of a trapped hydroperoxo form is quite consistent with behavior expected for the native cytochrome P450 cam enzyme, which has previously been shown to proceed directly at $77 \mathrm{~K}$ to the hydroperoxo form, with rather small fractions of the unprotonated species $\left(\mathrm{Fe}-\mathrm{OO}^{-}\right.$) being present in the preparations. ${ }^{7}$ Similarly, recent crystallographic studies of cryotrapped CPO Compound III also were interpreted to lead to radiation-induced conversion to the hydroperoxo form, with no evidence for a trapped peroxo-ligated species. ${ }^{25}$ Future studies with mutant proteins that 
restrict proton delivery to the $\mathrm{Fe}-\mathrm{O}-\mathrm{O}$ fragment and may facilitate systematic comparisons between oxygenated, peroxo, and hydroperoxo forms, are planned. Finally, the successful stabilization and structural characterization of these immediate precursors to the reactive products formed from $\mathrm{O}-\mathrm{O}$ bond cleavage may possibly lead to an effective strategy to structurally characterize fleeting intermediates that appear later in the cycle..$^{1-6}$

\section{Acknowledgment}

This work was supported by grants from the National Institutes of Health (DK35153 to J.R.K. and a Merit Award, R37GM31756, to S.G.S.). J.R.K. acknowledges support from the Pfletschinger Habermann Fund, Marquette University. We gratefully appreciate the help provided by Dr. John Bentley, Notre Dame Radiation Laboratory (Notre Dame University, IN), a facility of the U.S. Department of Energy, Office of Basic Energy Sciences.

\section{Supporting Information Available}

Figure S1 shows RR spectra of non-irradiated oxy adducts, while S2 and S3 show EPR and low-frequency RR spectra of cryoreduced form. This material is available free of charge via the Internet at http://pubs.acs.org.

\section{References}

${ }^{1}$ Ortiz de Montellano Paul, R., Ed. Cytochrome P450: Structure, Mechanism, and Biochemistry, 3rd ed.; Kluwer Academic/Plenum Publishers: New York, 2005.

2Shaik, S.; Kumar, D.; de Visser, S. P.; Altun, A.; Thiel, W. Chem. Rev. 2005, 105, 2279-2328.

${ }^{3}$ Denisov, I. G.; Makris, T. M.; Sligar, S. G.; Schlichting, I. Chem. Rev. 2005, $105,2253-2277$.

${ }^{4}$ Loew, G. H.; Harris, D. L. Chem. Rev. 2000, 100, 407-420.

5Zheng, J.; Wang, D.; Thiel, W.; Shaik, S. J. Am. Chem. Soc. 2006, 128, 13204-13215.

${ }^{6}$ Schlichting, I.; Berendzen, J.; Chu, K.; Stock, A. M.; Maves, S. A.; Benson, D. E.; Sweet, R. M.; Ringe, D.; Petsko, G. A.; Sligar, S. G. Science 2000, 287, 1615-1622.

7Davydov, R.; Makris, T. M.; Kofman, V.; Werst, D. E.; Sligar, S. G.; Hoffman, B. M. J. Am. Chem. Soc. 2001, 123, 1403-1415.

${ }^{8}$ Denisov, I. G.; Makris, T. M.; Sligar, S. G. Methods Enzymol. 2002, 357, $103-115$. 
${ }^{9}$ Sligar, S. G.; Makris, T. M.; Denisov, I. G. Biochem. Biophys. Res. Commun. 2005, 338, 346-354.

${ }^{10}$ Makris, T. M.; Denisov, I. G.; Schlichting, I.; Sligar, S. G. In Cytochrome P450: Structure, Function, Genetics, 3rd ed.; Ortiz de Montellano, P. R., Ed.; Kluwer Academic/Plenum Publishers: New York, 2004; pp 149-182.

${ }^{11}$ Kitagawa, T.; Mizutani, Y. Coord. Chem. Rev. 1994, 135/136, 685-735.

${ }^{12}$ Terner, J.; Palaniappan, V.; Gold, A.; Weiss, R.; Fitzgerald, M. M.; Sullivan, A. M.; Hosten, C. M. J. Inorg. Biochem. 2006, 100, 480-501.

${ }^{13}$ Kincaid, J. R. In The Porphyrin Handbook; Kadish, K. M., Smith, K. M., Guilard, R., Eds.; Academic Press: New York, 2000; Vol. 7, pp 225-291.

${ }^{14}$ Ibrahim, M.; Denisov, I. G.; Makris, T. M.; Kincaid, J. R.; Sligar, S. G. J. Am. Chem. Soc. 2003, 125, 13714-13718.

${ }^{15}$ Ibrahim, M.; Kincaid, J. R. J. Porphyrins Phthalocyanines 2004, 215-225.

${ }^{16}$ Bangcharoenpaurpong, O.; Rizos, A. K.; Champion, P. M.; Jollie, D.; Sligar, S. J. Biol. Chem. 1986, 261, 8089-8092.

${ }^{17} \mathrm{Hu}, \mathrm{S} . ;$ Schneider, A. J.; Kincaid, J. R. J. Am. Chem. Soc. 1991, 113, 4815-4822.

${ }^{18}$ MacDonald, I. D. G.; Sligar, S. G.; Christian, J. F.; Unno, M.; Champion, P. M. J. Am. Chem. Soc. 1999, 121, 376-380.

${ }^{19}$ Proniewicz, L. P.; Nakamoto, K.; Kincaid, J. R. J. Am. Chem. Soc. 1988, $110,4541-4545$.

${ }^{20}$ Oertling, W. A.; Kean, R. T.; Wever, R.; Babcock, G. T. Inorg. Chem. 1990, 29, 2633-2645.

${ }^{21}$ Ho, R. Y. N.; Roelfes, G.; Feringa, B. L.; Que, L., Jr. J. Am. Chem. Soc. 1999, 121, 264-265.

${ }^{22}$ Chen, P.; Fujisawa, K.; Solomon, E. I. J. Am. Chem. Soc. 2000, 122, 10177-10193.

${ }^{23}$ Lehnert, N.; Neese, F.; Ho, R. Y. N.; Que, L.; Solomon, E. I. J. Am. Chem. Soc. 2002, 124, 10810-10822.

${ }^{24}$ Rajani, C.; Kincaid, J. R.; Petering, D. H. J. Am. Chem. Soc. 2004, 126, 3829-3836.

${ }^{25}$ Kuhnel, K.; Derat, E.; Terner, J.; Shaik, S.; Schlichting, I. Proc. Natl. Acad. Sci. U.S.A. 2007, 104, 99-104. 